\title{
Endocrine dysfunctions in adults post hematopoietic stem cell transplantation
}

Carla Fernanda Nava ${ }^{1 *}$, Renata Carvalho de Alencar ${ }^{1}$, Fernanda Accioly de Andrade ${ }^{1}$, Luis Fernando Bouzas ${ }^{2}$, Rita de Cássia B. S. Tavares ${ }^{2}$, Leonardo Javier Arcuri ${ }^{2}$, Rossana Corbo Ramalho de Mello ${ }^{3}$, Daniel Alves Bulzico ${ }^{3}$, Cencita Hossana Cordeiro Noronha Pessoa ${ }^{3}$, Maria Alice Neves Bordallo ${ }^{3}$ and Fernanda Vaisman ${ }^{3}$

${ }^{1}$ Fellowship at Endocrine Service, National Cancer Institute (INCA), Rio de Janeiro - Brazil

${ }^{2}$ Bone Marrow Transplant, National Cancer Institute (INCA), Rio de Janeiro - Brazil

${ }^{3}$ Endocrine Service, National Cancer Institute (INCA), Rio de Janeiro - Brazil

\begin{abstract}
Introduction: Hematopoietic stem cell transplantation (HSCT) is the standard treatment for some malignancies and hematological diseases. Many patients/year undergoes this procedure and were at high risk of development long-term complications, including endocrine dysfunctions. The aim of this study is to evaluate the frequency and nature of endocrine disorders in adult patients undergoing HSCT in Brazil.

Materials and methods: Retrospective study from medical records of 494 post-HSCT patients, referred for follow-up in the Endocrinology Clinic of the National Cancer Institute (INCA).

Results and discussion: Three hundred forty-two patients met criteria for inclusion, of these $52.3 \%$ had endocrine complications post-HSCT. The main endocrine dysfunction was hypogonadism, followed by hypothyroidism, hypocortisolism and hypopituitarism. Graft-versus-host disease was diagnosed in $42.4 \%$ of total population. Seventy-three (21.3\%) patients of the cohort died during follow-up. Endocrine dysfunctions are common complications of HSCT. Early diagnosis and treatment can improve the quality of life and morbidity.
\end{abstract}

\section{Introduction}

Approximately 50,000 people/year worldwide undergo hematopoietic stem cell transplantation (HSCT) [1]. This is the standard treatment for patients with some hematological disorders and other malignancies [2]. HSCT is a complex and high cost procedure and only performed in countries with more than 300,000 inhabitants and more than 680 US\$ Gross National Income (GNI) per capita [1].

In the last decade, HSCT patients have achieved a survival rate never seen before. However, they develop chronic complications that impaired their quality of life and associated with significant morbidity and mortality [1], such as graft-versus-host disease (GVHD), endocrine failure, cataracts, bone necrosis and second malignancy [3].

The endocrine system is one of the most frequent targets of these chronic complications [4]. Available studies provide data on the pediatric population, little is known about the long-term effects in the adult population [4]. Endocrine dysfunction can appear earlier or later during the follow up, and the most common are gonadal, thyroid, pituitary and adrenal [5]. The risk factors for endocrine complications post-HSCT are influenced by the age at HSCT, use of TBI, previous pre-transplant therapies, conditioning for HSCT, irradiation schedule and the underlying disease [4,5].

In this context, searching and monitoring for early diagnosis of these pathologies are highly recommended. The aim of this study is to evaluate the frequency and nature of endocrine disorders in adult patients undergoing HSCT.

\section{Materials and methods}

\section{Study design}

This study was designed as a retrospective cohort study of medical records to direct research and consultation in electronic medical record held from $6^{\text {th }}$ May 2015 to $29^{\text {th }}$ September 2015.

\section{Patients}

Eligible cases were defined as all individuals who had undergone HSCT at National Cancer Institute (INCA), in Brazil, between June 1988 and June 2014, who had survived at least 1 year after transplant. Patients with age below 18 years at the time of HSCT were excluded. A minimum of two visits for endocrine evaluation was needed for enter in the study.

\section{Ethics aspects}

This study was approved by the Institution's Ethics Committee and was registered under registration number: 73/-09.

Correspondence to: Carla Fernanda Nava, Praça da Cruz Vermelha, 23 - Centro CEP 20230-130 - Rio de Janeiro - Brazil, Tel: 55021 3207-4625; E-mail: carlafernandanava@hotmail.com

Key words: hematopoietic stem cell transplantation, endocrine dysfunction, hypothyroidism, hypogonadism

Received: February 06, 2017; Accepted: February 24, 2017; Published: February 28,2017 


\section{Endpoints}

Were defined as primary endpoints the emergence of the following endocrine disorders post HSCT period: primary hypogonadism, primary hypothyroidism, primary hypocortisolism and hypopituitarism.

Male primary hypogonadism was considered present when there was a need for testosterone replacement - clinical symptoms plus low level of total testosterone and a level above laboratory limit of luteinizing hormone (LH) and/or follicle stimulating hormone (FSH). For the female, it was considered hypogonadal every patient who needed hormone replacement therapy (estrogen with or without progesterone) - clinical symptons with level of estradiol under laboratory limit and FSH and/or LH above laboratory limit; or to submit amenorrhea after HSCT.

For the definition of primary hypothyroidism we used thyroid stimulating hormone $(\mathrm{TSH})>10 \mathrm{mU} / \mathrm{L}$ with free $\mathrm{T} 4$ below normal limits [6], and/or the need for hormone replacement with LT4.

Primary hypocortisolism was defined if basal cortisol were $<3 \mu \mathrm{g} /$ dL without concomitant use of glucocorticoid and/or between $3-15$ $\mu \mathrm{g} / \mathrm{dL}$ in two different exams.

Hypopituitarism was defined by the presence of one or more pituitary deficiencies: gonadotropin ( $\mathrm{LH}$ and FSH), somatotropin (GH), thyrotropin (TSH) and corticotropin (ACTH). The gonadotropin deficiency (hypogonadotropic hypogonadism) was confirmed if there were low levels of FSH and LH plus estradiol and/or total testosterone below the lower limit of normal.

TSH deficiency was confirmed if there were low levels of free T4 with or without altered TSH in at least two steps. Adrenocorticotropic hormone $(\mathrm{ACTH})$ deficiency was documented if basal cortisol and ACTH were low $(<3 \mu \mathrm{g} / \mathrm{dL}$ and $<20 \mathrm{pg} / \mathrm{mL}$ respectively $)$ and excluded if basal cortisol $>15 \mu \mathrm{g} / \mathrm{dL}$ in two different occasions.

The endocrine function was assessed in patients immediately before and approximately 100 days post HSCT.

\section{Statistical analysis}

Continuous date is presented as mean and standard deviations with median values. For comparing medians nonparametric Mann-Whitney test was used and for categories we used Chi.square and Fisher's exact tests. Analysis was performed using SPSS software (Version 20.0 for Macintosh, IBM, SPSS, Chicago IL) and multivariate analysis with logistic regression.

\section{Results}

Four hundred and ninety four consecutive patients submitted to HSCT between June 1988 and June 2014 were referred for evaluation at the Endocrinology Clinic at the National Cancer Institute (INCA). From those, 152 were excluded from the analysis due to age, time of follow-up and lack of information. The remaining 342 were included in the final analysis (Figure 1).

As shown in Table 1, the majority were patients with Hodgkin's disease (HD) and submitted to autologous transplantation.

Pre HSCT conditioning therapy was done with CBV (cyclophosphamide, BCNU and VP-16) or BEAM (BCNU, VP16, Ara-C and Melphalan) for HD, NHD and MM, and with cyclophosphamide and bussulphan for CML, AML, MS, SAA, ALL, $\mathrm{PNH}, \mathrm{MF}$ and CLL, as recommended by standardized protocols.
494 transplant patients followed in an endocrinology service for adults

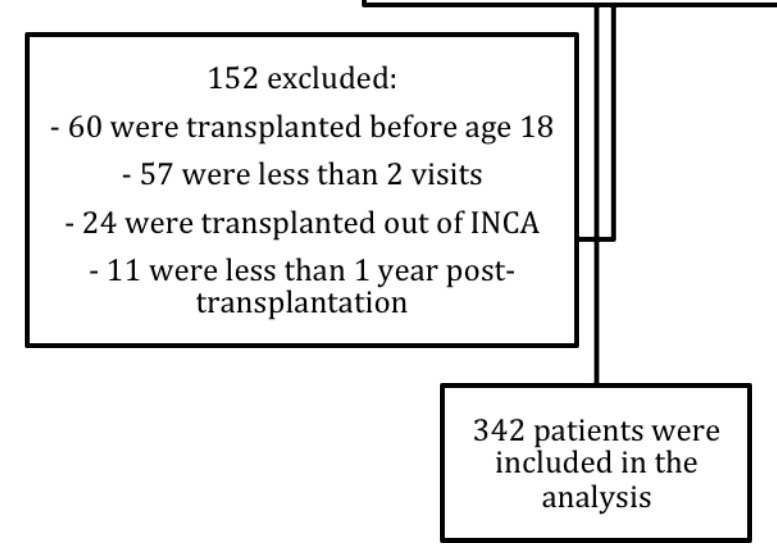

Figure 1. Description of patients and losses.

Table 1. Demographic and baseline clinical characteristics of patients. HSCT: hematopoietic stem cell transplantation; HD -Hodgkin's disease; CML - chronic myeloid leukemia; MM - multiple myeloma; NHD - non-hodgkin disease; AML - acute myelogenous leukemia; MS - myelodysplastic syndrome; SAA - severe aplastic anemia; ALL - acute lymphoid leukemia; PNH - paroxysmal nocturnal hemoglobinuria; MF - myelofibrosis; CLL chronic lymphocytic leukemia; ERT - external radiotherapy; GVHD: graft-versus-host disease.

\begin{tabular}{|c|c|c|}
\hline Characteristic & $\mathrm{N}=342$ & $\%$ \\
\hline Age at the HSCT & $37.7(18-68.6)$ & - \\
\hline Sex (F:M) & $175: 167$ & $51.2: 48.8$ \\
\hline \multicolumn{3}{|l|}{ Underlying Pathology } \\
\hline HD & 87 & 25.4 \\
\hline CML & 58 & 17 \\
\hline MM & 53 & 15.5 \\
\hline NHD & 40 & 11.7 \\
\hline AML & 36 & 10.5 \\
\hline MS & 24 & 7 \\
\hline SAA & 18 & 5.3 \\
\hline ALL & 15 & 4.4 \\
\hline PNH & 3 & 0.9 \\
\hline MF & 2 & 0.6 \\
\hline CLL & 1 & 0.3 \\
\hline Others & 5 & 1.5 \\
\hline \multicolumn{3}{|l|}{ Types of Transplant } \\
\hline Autologous & 177 & 51.8 \\
\hline Allogeneic related & 147 & 43 \\
\hline Allogeneic unrelated & 9 & 2.6 \\
\hline Mini allogeneic & 7 & 2 \\
\hline Syngeneic & 2 & 0.6 \\
\hline ERT & 92 & 26.9 \\
\hline Follow-up in Endocrinology (years) & $5.2(0.5-23.5)$ & - \\
\hline Endocrine Dysfunction pre HSCT & 79 & 23.1 \\
\hline Endocrine Dysfunction post HSCT & 263 & 52.3 \\
\hline GVHD & 145 & 42.4 \\
\hline Death & 73 & 21.3 \\
\hline
\end{tabular}

GVHD was diagnosed in 145 patients (87.8\%), complication associated with the types of allogeneic transplants. All required glucocorticoid therapy.

External radiotherapy (ERT) was performed in $26,9 \%$.

Seventy-three patients $(21,3 \%)$ died from disease.

Regarding endocrine dysfunction, 79 patients presented at least 
one hormone deficiency before the transplantation: 20 had primary hypothyroidism and 66 were women with primary hypogonadism (67\% were over 50 years old, with physiological menopause). Therefore 263 patients were further analyzed for new onset, post HSCT endocrinopathy. Table 2 shows the frequency of each endocrinopathy diagnosed post HSCT and the mean time for diagnosis.

ERT applied for the treatment of the underlying disease was the main risk factor for the development of primary hypothyroidism. When were performed at the manthle, 24 patients evolved to hypothyroidism vs 17 with euthyroidism $(\mathrm{p}<0.0001)$. No difference in this outcome was observed when ERT was performed in other sites. Type of conditioning, age, sex, total body irradiation, levels of free T4 in 100 days and steroid use had no statistical significance (Table 3). The underlying disease and the type of transplantation were risk factors in univariate analysis, but in the multivariate it appears linked to external radiotherapy. Seventy patients developed primary hypothyroidism and only two recovered thyroid function $(2.85 \%)$.

Women who developed primary hypogonadism more frequently were treated with bussulphan for pre HSCT conditioning therapy $(40.6 \%$ vs. 0). They had higher levels of serum FSH and LH and lower estradiol at the post-HSCT first visit (Table 4). Only two patients underwent pelvic ERT and both developed permanent hypogonadism, four irradiated the abdomen and three (75\%) remained with hypogonadism throughout follow-up.

Of the 96 patients with gonadal dysfunction after HSCT, only $12(12.5 \%)$ recovered ovarian function, allowing discontinuation of treatment.

Nine men developed primary hypogonadism, of these, only one recovered testicular function. Other data on male hypogonadism can be seen in table 5. Interestingly, three patients had high levels of FSH and LH (more than 2 times the upper limit of the reference range) during the entire follow-up period but with normal total testosterone levels and did not required treatment at any time. Total testosterone levels at the first visit were a significant factor to predict male hypogonadism along with pelvic ERT. High serum LH level but not FSH was significant to predict male hypogonadism.

Primary hypocortisolism and hypopituitarism occurred only in two patients respectively and were not evaluated.

Table 2. Frequency of endocrine dysfunction post HSCT $(n=263$ patients without endocrine dysfunction pre HSCT). HSCT - hematopoietic stem cell transplantation.

\begin{tabular}{|l|l|}
\hline Hypogonadism & $105(40.2 \%)$ \\
\hline Hypothyroidism & $70(26.8 \%)$ \\
\hline Hypopituitarism & $2(0.8 \%)$ \\
\hline Hypocortisolism & $2(0.8 \%)$ \\
\hline
\end{tabular}

Table 3. Risk factors for the development of primary hypothyroidism after HSCT. HSCT - Hematopoietic Stem Cell Transplantation; ERT - external radiotherapy; TBI - total body irradiation.

\begin{tabular}{|l|l|l|l|}
\hline Characteristic & $\begin{array}{l}\text { Hypothyroidism post HSCT } \\
(\mathbf{n}=\mathbf{7 0})\end{array}$ & $\begin{array}{l}\text { Euthyroidism } \\
(\mathbf{n = 1 9 3 )}\end{array}$ & p-value \\
\hline Age at HSCT & $30.3(18.4-61.2)$ & $35.3(18-68.6)$ & 0.4 \\
\hline Sex (F) & 35 & 117 & 0.1 \\
\hline TBI & 9 & 15 & 0.44 \\
\hline $\begin{array}{l}\text { TSH (mUI/L) in 100 } \\
\text { days }\end{array}$ & $3.43(0.16-89.07)$ & $2.11(0.13-8.9)$ & $\mathbf{0 . 0 1}$ \\
\hline Free T4 in 100 days & $1.0(0.1-1.6)$ & $1.0(0.6-1.8)$ & 0.12 \\
\hline Glucocorticoid use & 25 & 70 & 0.416 \\
\hline Follow-up (months) & $124(4-618.3)$ & $90.8(1-703.9)$ & $\mathbf{0 . 0 3 2}$ \\
\hline
\end{tabular}

Table 4. Risk factors for the development of primary hypogonadism (transient or permanent) in women. HSCT - Hematopoietic stem cell transplantation; GVHD - graftversus-host disease.

\begin{tabular}{|c|c|c|c|}
\hline Characteristic & $\begin{array}{l}\text { Hypogonadism post HSCT } \\
(\mathrm{n}=96)\end{array}$ & Eugonadism (n=11) & p-value \\
\hline $\begin{array}{l}\text { Age at the HSCT } \\
\text { (years) }\end{array}$ & $29(18-49)$ & $24(19-30)$ & 0.41 \\
\hline \multicolumn{4}{|l|}{ Conditioning } \\
\hline Bussulphan & $40.6 \%$ & $0 \%$ & 0.01 \\
\hline Cyclophosphamide & $53.1 \%$ & $45.5 \%$ & 0.56 \\
\hline ATG & $4.2 \%$ & $18.2 \%$ & 0.15 \\
\hline CBV & $37.5 \%$ & $54.5 \%$ & 0.39 \\
\hline Melphalan 200 & $6.2 \%$ & $0 \%$ & 0.67 \\
\hline GVHD & $47.9 \%$ & $27.3 \%$ & 0.23 \\
\hline Glucocorticoid use & $39.6 \%$ & $0 \%$ & 0.01 \\
\hline $\begin{array}{l}\mathrm{LH}(\mathrm{mUI} / \mathrm{L}) \text { in } 100 \\
\text { days }\end{array}$ & $57.1(26.3-178.4)$ & $10.5(0.1-48.6)$ & 0.001 \\
\hline $\begin{array}{l}\text { FSH }(\mathrm{mUI} / \mathrm{L}) \text { in } 100 \\
\text { days }\end{array}$ & $90.51(52.3-200)$ & $15.2(3.0-51.1)$ & 0.001 \\
\hline $\begin{array}{l}\text { Estradiol (ng/dl) in } \\
100 \text { days }\end{array}$ & $19.6(5.0-51.1)$ & $93.4(20-299)$ & 0.023 \\
\hline $\begin{array}{l}\text { Prolactin }(\mathrm{ng} / \mathrm{ml}) \text { in } \\
100 \text { days }\end{array}$ & $9.55(3-193)$ & $9.62(3-45)$ & 0.8 \\
\hline
\end{tabular}

Table 5. Risk factors for the development of primary hypogonadism (transient or permanent) in post HSCT men. HSCT - hematopoietic stem cell transplantation; GVHD graft-versus-host disease; ERT - external radiotherapy.

\begin{tabular}{|c|c|c|c|}
\hline Characteristic & $\begin{array}{l}\text { Hypogonadism post HSCT } \\
(\mathrm{n}=9)\end{array}$ & $\begin{array}{l}\text { Eugonadism } \\
(\mathrm{n}=146)\end{array}$ & p-value \\
\hline $\begin{array}{l}\text { Age at the HSCT } \\
\text { (years) }\end{array}$ & $50(29-65)$ & $39(18-68)$ & 0.45 \\
\hline \multicolumn{4}{|l|}{ Conditioning } \\
\hline Bussulphan & $11.1 \%$ & $38.7 \%$ & 0.23 \\
\hline Cyclophosphamide & $33.3 \%$ & $56.3 \%$ & 0.4 \\
\hline ATG & $0 \%$ & $4.9 \%$ & 0.7 \\
\hline CBV & $44.4 \%$ & $21.8 \%$ & 0.92 \\
\hline Melphalan 200 & $22.2 \%$ & $16.9 \%$ & 0.74 \\
\hline GVHD & $47.9 \%$ & $27.3 \%$ & 0.23 \\
\hline $\begin{array}{l}\text { ERT in the abdomen } \\
\text { and/or pelvis }\end{array}$ & $33.3 \%$ & $9.1 \%$ & 0.09 \\
\hline $\begin{array}{l}\mathrm{LH}(\mathrm{mUI} / \mathrm{L}) \text { in } 100 \\
\text { days }\end{array}$ & $8.7(2.5-27.6)$ & $7.9(1.1-66.3)$ & 0.07 \\
\hline $\begin{array}{l}\mathrm{FSH}(\mathrm{mUI} / \mathrm{L}) \text { in } 100 \\
\text { days }\end{array}$ & $21.8(6.9-54.4)$ & $17.5(2.7-75.2)$ & 0.53 \\
\hline $\begin{array}{l}\text { Total Testosterone }(\mathrm{ng} / \\
\mathrm{ml}) \text { in } 100 \text { days }\end{array}$ & $3.1(1.56-4.40)$ & $4.9(1.03-11.17)$ & 0.02 \\
\hline $\begin{array}{l}\text { Prolactin }(\mathrm{ng} / \mathrm{ml}) \text { in } \\
100 \text { days }\end{array}$ & $12.0(4.2-29.0)$ & $9,8(2.0-36.4)$ & 0.4 \\
\hline Glucocorticoid use & $44.4 \%$ & $36.6 \%$ & 0.83 \\
\hline
\end{tabular}

\section{Discussion}

This is the first study to report the frequency of endocrine dysfunction post-HSCT in a Brazilian population. In the present study, the most frequent endocrine dysfunction post-HSCT was primary hypogonadism followed by primary hypothyroidism. Around $47 \%$ of the HSCT were allogeneic and 52\% were autologous. Almost all patients that underwent allogeneic types of HSCT developed GVHD. That pathology can be acute or chronic and the treatment requires potent immunosuppressive, high doses of corticosteroids and affects significantly the quality of life of these patients. Seattle group [7] shows that GVHD can become chronic in about $10-50 \%$ of these patients and have an average duration of 3-5 years, which may delay the treatment and diagnosis of other post-HSCT dysfunctions.

The most common endocrine dysfunction post-HSCT in this study 
was hypogonadism. Gonadal failure in adult patients post-HSCT was found at a frequency of $40.2 \%$ but according to other studies, it can reach $92 \%$ in males and $99 \%$ in females on long-term follow-up [8] when transplanted children were included. As previously described by others authors [5,7-16], in our study risk factors for the development of hypogonadism were age at the transplant, type of conditioning and the treatments for the underlying disease (chemotherapy and ERT). A revision by Brennan, et al. [6] showed that gonadal failure was associated with age at transplant, conditioning and underlying disease therapy. Older patients had more hypogonadism and the probably of recover gonadal function decreases by a factor of 0.8 per year of age. Mertens, et al. [8] analyzed gonadal function of 270 patients post HSCT and showed the same association with age at transplant and gonadal failure. The older age at HSCT, the greater the chance of hypogonadism and an unusual recover of gonadal function. When looked at male hypogonadism, it is know that men's Leydig cells are the most resistant to treatment as showed by Kauppila, et al. [12], Keilholz, et al. [13] and Bordallo, et al. [17], and the germ cells are the most sensitive, leading to a laboratory pattern with little or no change in total testosterone and LH levels, with FSH elevation and possible infertility [18,19].

Regarding female hypogonadism, defined as low estradiol levels associated with elevated FSH and LH, only a few recovered ovarian function. These patients require hormone replacement therapy for prolonged periods due to the young age they developed hypogonadism (median 29 years old). One study [9] show that when gonadal recovery occurs, there are candidates for early menopause and high-risk pregnancies. We did not assessed this outcome.

The second most common endocrine dysfunction post-HSCT was primary hypothyroidism. It was associated with ERT performed during the treatment of the underlying disease, especially manthle ERT. The Seattle group [7] described hypothyroidism in $10-15 \%$ of those who received TBI, and Kauppila, et al. [12] showed that if the dose was $>20$ Gy it is more prevalent. In the present study TBI was not associated with primary hypothyroidism. Recover thyroid function was not common (less than 3\%). The damage was transitory in these cases, maybe because a transient hypothyroidism related to autoimmune thyroiditis post ERT as Majhaih, et al. [20] and Vantyghem, et al. [9] saw.

The use of glucocorticoids for a long-term in a high dose can temporarily change the hypothalamus-pituitary-adrenal axis, as confirmed by Majhail, et al. [20] and Vantyghem, et al. [9], and could impair the assessment of adrenal function. Some of our patients were using glucocorticoids at the first visit to endocrine service, but during the follow-up we can distinguish them. Hypocortisolism had low occurrence in our study and we did not consider it for the final analysis.

This study has some limitations. A very low frequency of hypocortisolism and hypopituitarism was seen. Provocative tests to assess pituitary and adrenal deficiencies were not available, so these two pathologies were not considered in the final evaluation. Other limitations were the lack of evaluation of infertility, which could better explain the effects of a high FSH in men post HSCT. Also, high hospitalization rates could influence and delay the diagnosis of endocrine dysfunctions.

\section{Conclusion}

Endocrine dysfunctions after HSCT are common and can cause significant impairment in quality of life of these patients. It is extremely necessary to pay attention to the symptoms and prevention and early treatment of these complications. The results of this study suggest that active monitoring in HSCT patients should be performed routinely.

\section{References}

1. Gratwohl A, Baldomero H, Aljurf M, Pasquini MC, Bouzas LF, et al. (2010) Hematopoietic stem cell transplantation A global perspective; For the Worldwide Network of Blood and Marrow Transplantation WBMT. JAMA 303: 1617-1624.

2. Léger CS, Nevill TJ (2004) Hematopoietic stem cell transplantation: a primer for the primary care physician. CMAJ 170: 1569-1577.[Crossref]

3. Hows JM, Passweg JR, Tichelli A, Locasciulli A, Szydlo R, et al. (2006) Comparison of long-term outcomes after allogeneic hematopoietic stem cell transplantation from matched sibling and unrelated donors. Bone Marrow Transplant 38: 799-805.

4. Orio F, Muscogiuri G, Palomba S, Serio B, Sessa M, et al. (2014) Endocrinopathies after allogeneic and autologous transplantation of hematopoietic stem cells. Scientific World Journal 282147

5. Brennan BM, Shalet SM (2002) Endocrine late effects after bone marrow transplant. $\mathrm{Br}$ J Haematol 118: 58-66.[Crossref]

6. Garber JR, Cobin RH, Gharib H, Hennessey JV, Klein I, et al. (2012) Clinical practice guidelines for hypothyroidism in adults: cosponsored by the American Association of Clinical Endocrinologists and the American Thyroid Association. Thyroid 22: 12001235.

7. Syrjala KL, Martin PJ, Lee SJ (2012) Delivering care to long-term adult survivors of hematopoietic cell transplantation. J Clin Oncol 30: 3746-3751.[Crossref]

8. Mertens AC, Ramsay NK, Kouris S, Neglia JP (1998) Patterns of gonadal dysfunction following bone marrow transplantation. Bone Marrow Transplant 22: 345-350. [Crossref]

9. Vantyghem MC, Cornillon J, Decanter C, Defrance F, Karrouz W, et al. (2014) Management of endocrino-metabolic dysfunctions after allogeneic hematopoietic stem cell transplantation. Orphanet J Rare Dis 9: 162.

10. Buchbinder D, Nugent DJ, Brazauskas R, Wang Z, Aljurf MD, et al. (2012) Late effects in hematopoietic cell transplant recipients with acquired severe aplastic anemia: a report from the late effects working committee of the center for international blood and marrow transplant research. Biol Blood Marrow Transplant 18: 1776-1784.

11. Abou-Mourad YR, Lau BC, Barnett MJ, Forrest DL, Hogge DE, et al. (2010) Long-term outcome after allo-SCT: close follow-up on a large cohort treated with myeloablative regimens. Bone Marrow Transplant 45: 295-302.[Crossref]

12. Kauppila M, Koskinen P, Irjala K, Remes K, Viikari J (1998) Long-term effects of allogeneic bone marrow transplantation (BMT) on pituitary, gonad, thyroid and adrenal function in adults. Bone Marrow Transplant 22: 331-337. [Crossref]

13. Keilholz U, Körbling M, Fehrentz D, Bauer H, Hunstein W (1989) Long-term endocrine toxicity of myeloablative treatment followed by autologous bone marrow/blood derived stem cell transplantation in patients with malignant lymphohematopoietic disorders. Cancer 64: 641-645.

14. Hilgendorf I, Greinix H, Halter JP, Lawitschka A, Bertz H, et al. (2015) Long-term follow-up after allogeneic stem cell transplantation. Dtsch Arztebl Int 112: 51-58. [Crossref]

15. Darzy KH (2009) Radiation-induced hypopituitarism after cancer therapy: who, how and when to test. Nat Clin Pract Endocrinol Metab 5: 88-99.

16. Gundgurthi A, Garg MK, Nair V, Pakhetra R, Das S, et al. (2013) Endocrine complications after busulphan and cyclophosphamide based hematopoietic stem cell transplant: A single tertiary care centre experience. Indian J Endocrinol Metab 17: 855863.

17. Bordallo MA, Guimarães MM, Pessoa CH, Carriço MK, Dimetz T, et al. (2004) Decreased serum inhibin B/FSH ratio as a marker of Sertoli cell function in male survivors after chemotherapy in childhood and adolescence. $J$ Pediatr Endocrinol Metab 17: 879-887.

18. Schimmer AD, Ali V, Stewart AK, Imrie K, Keating A (2001) Male sexual function after autologous blood or marrow transplantation. Biol Blood Marrow Transplant 7: 279-283. 
Nava CF (2017) Endocrine dysfunctions in adults post hematopoietic stem cell transplantation

19. Chatterjee R, Kottaridis PD, McGarrigle HH, Eliahoo J, McKeag N, et al. (2001) Patterns of Leydig cell insufficiency in adult males following bone marrow transplantation for haematological malignancies. Bone Marrow Transplant 28: 497-502.
20. Majhail NS, Rizzo JD, Lee SJ, Aljurf M, Atsuta Y, et al. (2012) Recommended Screening and Preventive Practices for Long-Term Survivors after Hematopoietic Cell Transplantation.Bone Marrow Transplant 47: 337-341.

Copyright: @2017 Nava CF. This is an open-access article distributed under the terms of the Creative Commons Attribution License, which permits unrestricted use, distribution, and reproduction in any medium, provided the original author and source are credited. 